\title{
Comment on "Possible prophylactic or preventive role of topical povidone iodine during accidental ocular exposure to 2019-nCoV"
}

\author{
Rinky Agarwal $^{1} \cdot$ Dewang Angmo $^{1}$ (i) $\cdot$ Rohit Saxena $^{1} \cdot$ Namrata Sharma $^{1}$
}

Received: 26 June 2020 / Revised: 26 June 2020 / Accepted: 23 July 2020 / Published online: 3 August 2020

(C) Springer-Verlag GmbH Germany, part of Springer Nature 2020

\section{Dear Editor,}

Recent ongoing pandemic infuriated by SARS-CoV-2 virus has created turmoil in the entire world. Researchers and clinicians globally are working tirelessly to assemble and correlate all data on this virus to elucidate its pathogenesis and devise a concrete plan for its control. In this regard, a recent article published by "Sarma et al." in your esteemed journal suggesting a theoretical use of povidone-iodine $1 \%$ eye drop for post-exposure prophylaxis (PEP) after accidental ocular exposure to the virus has particularly caught our attention [1].

Povidone-iodine (PVP-I) is a complex of polyvinylpyrrolidone and iodine. It is a powerful disinfectant with broad-spectrum antimicrobial effect and is routinely used in ophthalmology for preoperative preparation of the ocular surface and adnexa. However, we are concerned regarding its usage for PEP after accidental ophthalmic exposure due to the following reasons.

SARS-CoV-2 is primarily a respiratory system virus with aerodigestive spread. The presence of virus in the ocular secretions and its ability to enter the systemic circulation through accidental hand-eye contact are largely unknown due to doubtful presence and action of ACE-2 receptors in the corneal and conjunctival epithelium [2]. Both asymptomatic individuals and patients with active COVID-19 infection (systemic as well as ophthalmic) have a potentially low risk of shedding virus in ocular secretions, and even this decreases progressively with time. So, use of prophylactic PVP-I for accidental ocular exposure without gauging the infectivity status of the patient seems a little unrealistic and improbable. Same holds true for a course of self-limiting and seemingly benign COVID-19-related conjunctivitis.

Dewang Angmo

dewang45@gmail.com

1 Dr Rajendra Prasad Centre for Ophthalmic Sciences, AIIMS, New Delhi, India
While PVP-I is an efficacious antimicrobial agent, its utility for adenoviral conjunctivitis as regarded by the authors mandates larger studies [3, 4]. Additionally, the reference that the authors cite for comparable efficacy between PVP-I 1\% applied for $2 \mathrm{~min}$ and $70 \%$ ethanol in reducing viral infectivity to below detectable level relates to a study undertaken in 2006 that explores the efficacy of PVP-I on SARS-CoV virus in non-ocular tissues and not on SARS-CoV-2 virus in ocular tissues $[5,6]$. Extrapolating it to present scenario may not be appropriate, and therefore, further evaluation is required to determine the actual effect of PVP-I on the COVID-19 virus present in ocular surface.

Devising an appropriate treatment regime is imperative for a maximum effect and minimal toxicity of PVP-I. Recently, Gui et al. proposed $15 \mathrm{~s}$ long gargles with PVP-I $1 \%$ multiple times a day in the early phases of active infection to prevent virus transmission [7]. For healthcare workers dealing with high-risk patients, Leila Mady et al. endorsed nasal irrigation with $240 \mathrm{~mL}$ of $0.4 \%$ PVP-I solution or oral/oropharyngeal wash with $10 \mathrm{~mL}$ of $0.5 \%$ aqueous PVP-I solution in addition to appropriate personal protective equipment (PPE) to attenuate nosocomial transmission of COVID-19 [8]. Even in these aerodigestive areas with high viral loads, concentrations lower than $1 \%$ are recommended. Therefore, $1 \%$ PVP-I concentration as suggested by the authors is arbitrary and mandates larger studies. Also, considering a study by Liang et al. where they showed that the antimicrobial effect of $0.2 \%$ PVP-I solution instilled into the conjunctiva of a live dog for $2 \mathrm{~min}$ without being washed out was comparable with $1.0 \%$ and $5.0 \%$ PVP-I solutions in humans and repeated dosing of concentrations as low as $0.6 \%$ PVP-I gel could be oculo-toxic, a separate treatment regime needs to be devised for frequent instillations for COVID-19-related conjunctivitis [6].

Besides need, safety, and efficacy, the mode of administration of PVP-I also needs to be considered. For example, De Kaspar and associates reported fewer positive conjunctival bacterial cultures with $10 \mathrm{~mL}$ conjunctival irrigation of $5 \%$ solution compared with two drops of $5 \%$ povidone-iodine 
due to the ability of the former to reach the conjunctival crypts, especially those located in the fornices [9]. If we presume a reasonable efficacy of PVP-I against SARS-CoV-2 virus, the use of drops alone may not offer protection to entire ocular surface accidentally exposed to the virus. In these cases, painting of entire surface may be required for PEP.

Coming to toxicity of topical PVP-I, the stinging sensation induced by this drug on a non-anesthetized eye could result in rubbing of eyes that may predispose it to microbial invasion from epithelial microtrauma. Whether a topical anesthetic is needed to combat this mandates further evaluation, and if needed, then adverse effects of the former on corneal epithelium should not be ignored. In the highly unusual cases with allergy to PVP-I or its relevant excipients and relative contraindications to iodine, future studies on alternative methods of PEP are advocated.

To summarize, until definitive studies prove supporting results, usage of PVP-I for PEP after accidental ocular exposure to SARS-CoV-2 remains doubtful. We personally recommend adequate use of PPE inclusive of face shields, masks, goggles, and gown to avoid such accidental contacts rather than a blanket PVP-I PEP which may give a false sense of assurance without any proven efficacy and safety.

\section{Compliance with ethical standards}

Conflict of interest The authors declare that they have no conflict of interest.

\section{References}

1. Sarma P, Kaur H, Medhi B et al (2020) Possible prophylactic or preventive role of topical povidone iodine during accidental ocular exposure to 2019-nCoV [published online ahead of print]. Graefes Arch Clin Exp Ophthalmol 2020:1-3. https://doi.org/10.1007/ s00417-020-04752-2

2. Lange C, Wolf J, Auw-Haedrich C et al (2020) Expression of the COVID-19 receptor ACE2 in the human conjunctiva [published online ahead of print, 2020 May 6]. J Med Virol. https://doi.org/10. 1002/jmv.25981

3. Isenberg SJ, Apt L, Valenton M et al (2002) A controlled trial of povidone-iodine to treat infectious conjunctivitis in children. Am J Ophthalmol 134:681Đ688

4. Pepose JS, Narvekar A, Liu W et al (2019) A randomized controlled trial of povidone-iodine/dexamethasone ophthalmic suspension for acute viral conjunctivitis. Clin Ophthalmol 13:535-544. Published 2019 Mar 21. https://doi.org/10.2147/OPTH.S191275

5. Kariwa H, Fujii N, Takashima I (2006) Inactivation of SARS coronavirus by means of povidone-iodine, physical conditions and chemical reagents. Dermatology (Basel, Switzerland) 212(Suppl 1):119-123

6. Liang B, Yuan X, Wei G et al (2020;2020.05.18.103184. Published 2020 May 20) In-vivo toxicity studies and in-vitro inactivation of SARS-CoV-2 by povidone-iodine in-situ gel forming formulations. Preprint. bioRxiv. https://doi.org/10.1101/2020.05.18.103184

7. Gui D, Pepe G, Magalini S (2020) Just one more hygiene practice in COVID-19. Eur Rev Med Pharmacol Sci 24(7):3438-3439. https:// doi.org/10.26355/eurrev_202004_20796

8. Mady LJ, Kubik MW, Baddour K et al (2020) Consideration of povidone-iodine as a public health intervention for COVID-19: utilization as "personal protective equipment" for frontline providers exposed in high-risk head and neck and skull base oncology care. Oral Oncol 105:104724. https://doi.org/10.1016/j.oraloncology. 2020.104724

9. De Kaspar MH, Chang RT, Singh K et al (2005) Prospective randomized comparison of 2 different methods of $5 \%$ povidone-iodine applications for anterior segment intraocular surgery. Arch Ophthalmol 123(2):161-165

Publisher's note Springer Nature remains neutral with regard to jurisdictional claims in published maps and institutional affiliations. 